\title{
SORGO SACARINO EM DIFERENTES ARRANJOS DE PLANTAS E LOCALIDADES DE MINAS GERAIS, BRASIL
}

\author{
CARLOS JULIANO BRANT ALBUQUERQUE ${ }^{1}$, FLÁVIO DESSAUNE TARDIN², \\ RAFAEL AUGUSTO DA COSTA PARRELLA², ADRIANO DE SOUZA GUIMARÃES ${ }^{1}$, \\ RENATO MENDES DE OLIVEIRA ${ }^{3}$ e KAREN MARCELLE DE JESUS SILVA ${ }^{4}$
}

\begin{abstract}
${ }^{1}$ Pesquisador, Epamig, Bolsista Fapemig, Uberlândia, MG, Brasil, carlosjuliano@epamig.br,adriano.guimaraes@epamig.br ${ }^{2}$ Pesquisador,Embrapa Milho e Sorgo, Sete Lagoas, MG, Brasil,tardin@cnpms.embrapa.br, parrella@cnpms.embrapa.br ${ }^{3}$ Mestrando em Agronomia, Unimontes (Campus Janaúba), Janaúba, MG, Brasil, renatoagronomo@hotmail.com ${ }^{4}$ Bolsista Fapemig, Epamig, Uberlândia, MG, Brasil, karen_marcelle@hotmail.com
\end{abstract}

Revista Brasileira de Milho e Sorgo, v.11, n.1, p. 69-85, 2012

\begin{abstract}
RESUMO - O objetivo deste trabalho foi avaliar a produtividade e a qualidade do caldo de cultivares de sorgo sacarino em diferentes arranjos de plantas. Foram instalados experimentos em três localidades no estado de Minas Gerais, Brasil. Em cada local, o experimento foi conduzido conforme o delineamento experimental em blocos casualizados, em esquema fatorial $2 \times 4 \times 4 \times 3$ com quatro repetições, sendo duas cultivares (BRS 506 e BRS 507), quatro densidades de plantas $\left(100,140,180\right.$ e 220 mil plantas ha $\left.{ }^{-1}\right)$, quatro espaçamentos entre linhas $(50,70,90$ e $110 \mathrm{~cm})$ e três localidades do estado de Minas Gerais (Nova Porteirinha, Leme do Prado e Jaíba). Foram analisados altura das plantas, produtividade de massa fresca, massa do caldo e Brix do caldo. $\mathrm{O}$ aumento da população proporciona maiores produtividade de massa fresca e massa do caldo nas duas cultivares. A localidade afeta a produtividade de massa fresca e a massa do caldo e o Brix do sorgo sacarino independente do arranjo de plantas. A redução do espaçamento proporciona maiores produtividade de massa fresca e massa do caldo em função do local.
\end{abstract}

Palavras-chave: brix, densidade, espaçamento, etanol, Sorghum bicolor.

\section{SWEET SORGHUM IN DIFFERENT ROW SPACING AND PLANT DENSITIES IN MINAS GERAIS STATE, BRAZIL}

\begin{abstract}
The objective of this study was to evaluate the productivity and quality of the juice of sweet sorghum cultivars at different row spacings and plant densities. Experiments were carried out in three localities of Minas Gerais State, Brazil. In each site the trial was conducted in a randomized complete block design, in a factorial $2 \times 4 \times 4$ scheme, with four replications, comprising two genotypes (BRS 506 and BRS 507), four plant densities (100, 140, 180 and 220 thousand plants ha ${ }^{-1}$ ), four row spacings $(50,70,90$ and $110 \mathrm{~cm}$ ) and three locations in the State of Minas Gerais (Nova Porteirinha, Leme do Prado and Jaíba). Plant height, productivity of green matter, juice yield and Brix of the juice were analyzed. The increase in population provided higher productivity of green matter and juice in the two cultivars. The location affected the green matter productivity, juice productivity and Brix of sweet sorghum, independent of plant arrangement. Reduction of row spacing caused higher productivity of fresh mass and juice mass as a function of location.
\end{abstract}

Key words: brix, density, row spacing, ethanol, Sorghum bicolor. 
Os serviços de transporte de países industrializados são baseados primariamente em combustíveis fósseis. Desde a crise do petróleo na década de 1970 e o reconhecimento das limitações dos recursos petrolíferos mundiais, a tecnologia de produção de combustíveis de origem vegetal tem recebido atenção especial. Outra argumentação para o cultivo de plantas para a produção de etanol é a preocupação com a redução do volume de emissões de gases causadores do efeito estufa, como determina o Protocolo de Kyoto.

O caldo do sorgo sacarino pode ser utilizado na produção de etanol de primeira geração, através de processo fermentativo, enquanto suas fibras, principais componentes do bagaço, podem ser usadas como forragem para alimentação animal, co-geração de eletricidade ou matéria-prima para produção de etanol de segunda geração através de hidrólise enzimática, que transforma a celulose em açúcares fermentáveis.

O etanol é responsável por $90 \%$ do total dos biocombustíveis produzidos em diferentes partes do mundo (Prabu \& Murugesan, 2011), podendo ser utilizado de diversas formas. No Brasil, é comum o uso de veículos flex abastecidos com etanol ou gasolina.

O desafio para as indústrias de biocombustíveis é o desenvolvimento de uma biorrefinaria economicamente viável e sustentável. As usinas de produção de etanol existentes no Brasil operam suas máquinas entre seis e oito meses por ano, apresentando uma entressafra de pelo menos quatro meses. O sorgo sacarino na entressafra da cana, como matéria-prima para produção de etanol, tem potencial para diminuir a ociosidade das máquinas das usinas neste período, pois os mesmos equipamentos de moagem, fermentação e destilação utilizados para a produção de etanol a partir da cana-de-açúcar podem ser empregados para a fabricação de etanol a partir de sorgo. Sendo assim, o sorgo sacarino poderá servir de matéria-prima complementar ou mesmo substituir a cana-de-açúcar no verão. Nessa época, os canaviais apresentam menor concentração de sacarose nos colmos devido à idade da planta. Logo, o desenvolvimento de sistemas de produção para o sorgo sacarino é fundamental para viabilizar economicamente o seu cultivo.

O sorgo é uma espécie C4 com grande eficiência na utilização da radiação solar por meio da fotossíntese, que é afetada pela quantidade de luz ativa interceptada pela estrutura do dossel e pela distribuição ao longo do dossel (Magalhães \& Durães, 2003). Diversas práticas culturais são importantes na produção vegetal. Entre as práticas culturais empregadas para a obtenção de maior produção das espécies vegetais, a escolha do melhor arranjo de plantas é importante por favorecer o controle de invasoras e maior eficiência no aproveitamento dos recursos do ambiente, como luz e água.

Ao definir o melhor arranjo das plantas na área, espera-se adequar o melhor espaçamento e a melhor população para cada cultivar. Considerando o sorgo forrageiro e o sorgo granífero, diversos autores reportaram a importância do arranjo de plantas na obtenção de maiores rendimentos (Jones \& Johnson, 1997; Baumhardt \& Howell, 2006; Albuquerque et al. 2011). Estes autores demonstraram aumento na produtividade de grãos e/ou de matéria seca em função do arranjo de plantas na área; entretanto, para o sorgo sacarino, experimentos com essas informações são incipientes.

Alguns trabalhos envolvendo melhoramento e tratos culturais com cultivares de sorgo sacarino, granífero e forrageiro foram realizados nas décadas de 1970 e 1980 (Santos, 1979; Silva, 1979; Casela et al.,1986). Entretanto, muitas pesquisas não tiveram 
continuidade. Atualmente, sistemas de produção estão sendo readaptados em função das novas tendências da agricultura moderna. Sendo assim, objetivouse neste trabalho avaliar a produtividade de biomassa fresca, massa de caldo e Brix do caldo de cultivares de sorgo sacarino em diferentes espaçamentos, densidades de plantas e localidades do estado de Minas Gerais, Brasil.

\section{Material e Métodos}

Os ensaios foram conduzidos em áreas experimentais da Epamig na Feac (Fazenda Experimental de Acauã), na Feja (Fazenda Experimental de Jaíba) e na FEGR (Fazenda Experimental do Gorutuba).

A Feac está localizada no município de Leme do Prado, MG, Brasil, nas coordenadas com latitude $17^{\circ} 03^{\prime}$ S e longitude $42^{\circ} 48^{\prime} \mathrm{W}$ a uma altitude de 812 m. A Feja situa-se a $12 \mathrm{~km}$ da cidade de Jaíba, MG, Brasil, nas coordenadas $15^{\circ} 16^{\prime} \mathrm{S}$ e $43^{\circ} 40^{\prime} \mathrm{W}$, a uma altitude de $456 \mathrm{~m}$ e a FEGR localiza-se no perímetro irrigado do Gorutuba, no município de Nova Porteirinha, MG, Brasil, nas coordenadas $14^{\circ} 47^{\prime} \mathrm{S}$ e $43^{\circ} 18^{\prime}$ $\mathrm{W}$, a uma altitude de $516 \mathrm{~m}$.

Os experimentos foram implantados em regime de sequeiro na primeira quinzena de dezembro/2009 e conduzidos até a primeira quinzena de março/2012. Os dados sobre variações na temperatura e na precipitação média por decêndios, durante a condução dos experimentos em cada localidade, são apresentados na Figura 1.

A fertilidade e a textura dos solos nas três localidades são apresentadas por meio dos resultados das análises na Tabela 1.

Foram utilizados os materiais genéticos provenientes da Embrapa (Empresa Brasileira de Pes- quisa Agropecuária). $\mathrm{O}$ experimento foi conduzido conforme o delineamento experimental em blocos casualizados, em esquema fatorial 2 x 4 × 4 × 3, com quatro repetições, sendo duas cultivares (BRS 506 e BRS 507), quatro densidades de plantas (100, 140, 180 e 220 mil plantas $h^{-1}$ ), quatro espaçamentos entre linhas (50, 70, 90 e $110 \mathrm{~cm})$ e três localidades (Leme do Prado, Jaíba e Nova Porteirinha). A parcela experimental foi constituída de quatro linhas de $5 \mathrm{~m}$ de comprimento e a área útil foi formada pelas duas linhas ventrais, onde foram coletados todos os dados.

No experimento conduzido em Leme do Prado, utilizou-se 3,0 t ha ${ }^{-1}$ de calcário dolomítico (PRNT de 80\%) para correção da acidez do solo e neutralização do alumínio tóxico. Em todos os locais, após aração e gradagem, foram feitos os sulcos nos diferentes espaçamentos em função dos tratamentos sorteados ao acaso para posterior adubação de plantio e semeadura manual. Como o cultivo do sorgo é realizado em condições marginais, optou-se por utilizar $100 \%$ a mais de sementes para posterior desbaste nas populações desejadas.

As adubações de plantio e de cobertura foram realizadas considerando a área útil dos diferentes espaçamentos. Para todos os ensaios, foram utilizados $400 \mathrm{~kg} \mathrm{ha}^{-1}$ da fórmula 04-30-10 mais 0,5\% de Zn. Realizou-se adubação de cobertura com 90 $\mathrm{kg} \mathrm{ha}^{-1}$ de $\mathrm{K}_{2} \mathrm{O}$ (cloreto de potássio) e $90 \mathrm{~kg} \mathrm{ha}^{-1}$ de $\mathrm{N}$ (ureia). O controle de plantas daninhas foi realizado em pós-emergência com herbicida à base de atrazina na dosagem de $31 \mathrm{ha}^{-1}$ do produto comercial. Realizaram-se pulverizações, por meio de um pulverizador costal, com o inseticida deltametrina, na dosagem de $200 \mathrm{ml} \mathrm{ha}^{-1}$, para controle da lagartado-cartucho, Spodoptera frugiperda (J. E. Smith) (Lepidoptera: Noctuidae). 


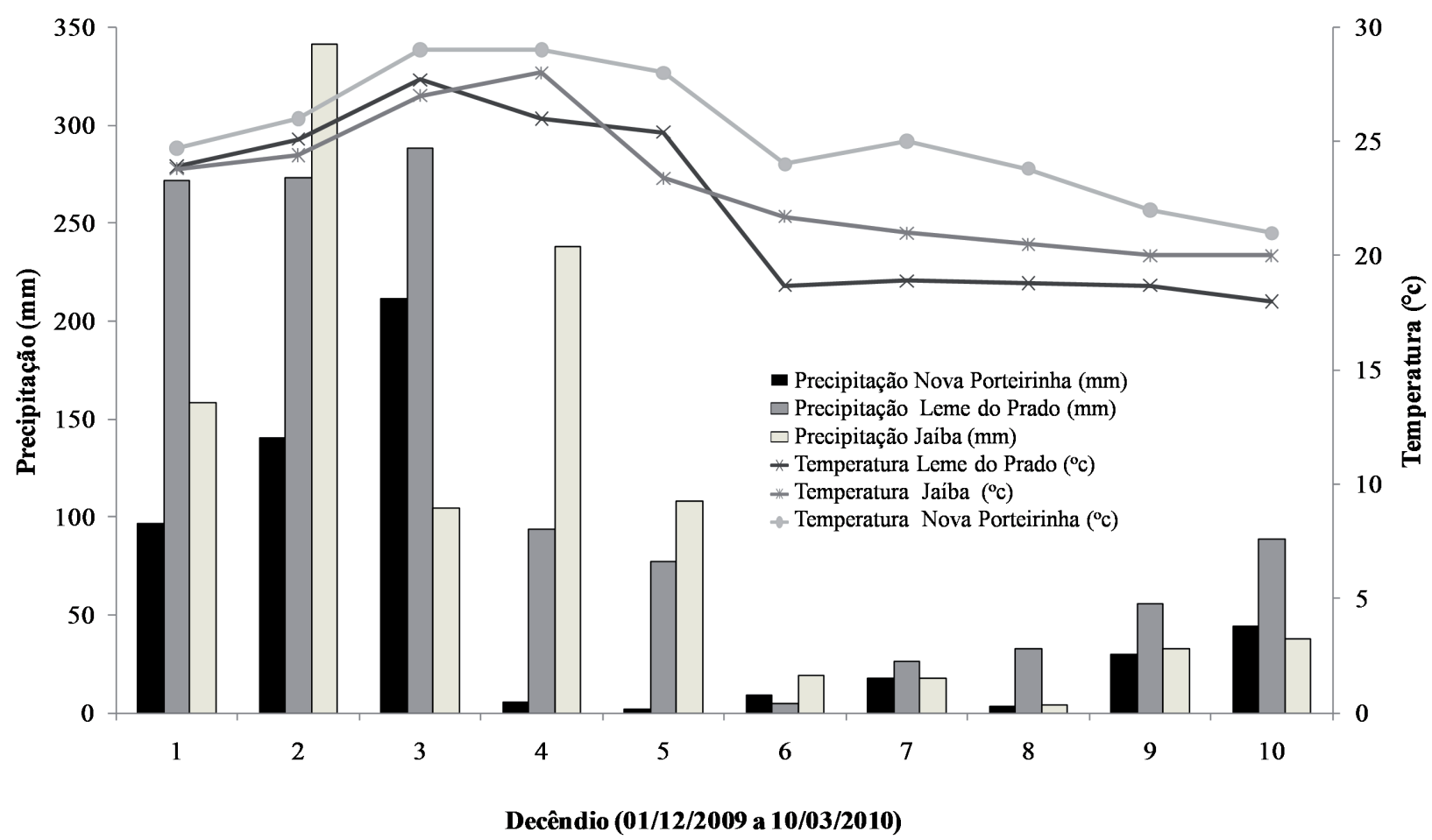

FIGURA 1. Dados médios de temperatura e precipitação pluvial por decêndio, em Jaíba, Nova Porteirinha e Leme do Prado de 01/12/2009 a 10/04/2010. Dados obtidos nas estações meteorológicas da Epamig localizadas nas respectivas fazendas experimentais.

Foram avaliados os dados referentes à altura de plantas, à massa fresca da planta, à massa do caldo e ao Brix.

As alturas de plantas foram tomadas após o florescimento, considerando a média geral da parcela, tendo como referência o solo até a base da panícula. As colheitas dos experimentos iniciaram-se quando os grãos das panículas atingiram a maturidade fisiológica, conforme recomendado por Teixeira et al. (1999). Pesaram-se todas as plantas da área útil da parcela para obtenção da massa fresca da planta toda (colmo, folha e panícula). Em seguida, retirou-se uma amostra de dez plantas ao acaso para análise da massa do caldo e do Brix. A massa do caldo foi retirada por meio de um moinho artesanal elétrico com "baixa efi- ciência de extração". As folhas e os colmos das plantas foram processados no moinho individualmente para extração do caldo com a finalidade de reduzir as perdas. Posteriormente, avaliou-se o Brix através do refratômetro de leitura digital. A massa do caldo das parcelas foi estimada através da relação do peso do caldo e do peso da massa fresca das dez plantas com o peso total da massa fresca das parcelas. Os dados referentes ao peso de massa fresca e ao peso do caldo das parcelas foram transformador para $\mathrm{tha}^{-1}$, considerando-se os respectivos espaçamentos adotados.

Os dados obtidos foram submetidos, inicialmente, a uma análise de variância individual por experimento. Em seguida, foram realizados os testes de aditividade dos dados, 
TABELA 1. Resultados das análises de amostras de solo $(0-20 \mathrm{~cm}$ de profundidade $)$ da área experimental. Laboratório de fertilidade dos solos, Epamig Nova Porteirinha, MG.

\begin{tabular}{|c|c|c|c|}
\hline Características químicas & Jaíba, MG & Nova Porteirinha, MG & Leme do Prado, MG \\
\hline $\mathrm{pH}$ em $\mathrm{H}_{2} \mathrm{O}$ & 7,2 & 6,2 & 5,9 \\
\hline $\mathrm{H}+\mathrm{Al}\left(\mathrm{cmolc} \mathrm{dm}^{-3}\right)$ & 1,1 & 1,5 & 5,4 \\
\hline $\mathrm{Al}\left(\mathrm{cmolc} \mathrm{dm}^{-3}\right)$ & 0,0 & 0,0 & 0,4 \\
\hline $\mathrm{Ca}\left(\mathrm{cmolc} \mathrm{dm}^{-3}\right)$ & 10,1 & 2,0 & 4,9 \\
\hline $\operatorname{Mg}\left(\mathrm{cmolc} \mathrm{dm}{ }^{-3}\right)$ & 1,6 & 0,6 & 1,3 \\
\hline $\mathrm{K}\left(\mathrm{mg} \mathrm{dm}^{-3}\right)$ & 206 & 173 & 102 \\
\hline $\mathrm{P}\left(\mathrm{mg} \mathrm{dm} \mathrm{m}^{-3}\right)$ & 13,1 & 39,0 & 23,1 \\
\hline $\mathrm{Zn}\left(\mathrm{mg} \mathrm{dm}^{-3}\right)$ & 6,4 & 5,3 & 0,9 \\
\hline $\mathrm{Fe}\left(\mathrm{mg} \mathrm{dm}^{-3}\right)$ & 10,2 & 103,5 & 30,0 \\
\hline $\operatorname{Mn}\left(\mathrm{mg} \mathrm{dm}^{-3}\right)$ & 145,4 & 18,0 & 7,7 \\
\hline $\mathrm{Cu}\left(\mathrm{mg} \mathrm{dm}^{-3}\right)$ & 1,6 & 0,2 & 0,3 \\
\hline $\mathrm{B}\left(\mathrm{mg} \mathrm{dm}^{-3}\right)$ & 0,9 & 0,3 & 0,5 \\
\hline Mat. org. (dag kg-1) & 2,1 & 0,7 & 4,9 \\
\hline $\mathrm{SB}\left(\mathrm{cmolc} \mathrm{dm}^{-3}\right)$ & 12,4 & 3,1 & 6,6 \\
\hline $\mathrm{T}\left(\mathrm{cmolc} \mathrm{dm}^{-3}\right)$ & 13,4 & 4,6 & 11,9 \\
\hline $\left.\mathrm{t}(\mathrm{cmolc} \mathrm{dm})^{3}\right)$ & 12,4 & 3,1 & 7,0 \\
\hline $\mathrm{V}(\%)$ & 92 & 68 & 55 \\
\hline m $(\%)$ & 0 & 0 & 6 \\
\hline \multicolumn{4}{|l|}{ Características físicas } \\
\hline Areia $\left(\right.$ dag kg $\left.{ }^{-1}\right)$ & 23 & 66 & 30 \\
\hline Silte $\left(\right.$ dag kg $\left.{ }^{-1}\right)$ & 40 & 19 & 29 \\
\hline Argila (dag kg-1) & 37 & 15 & 41 \\
\hline Classe textural & Franco Argiloso & Franco Arenoso & Argiloso \\
\hline
\end{tabular}

normalidade dos erros e homogeneidade das variâncias. Posteriormente, foi realizada análise de variância conjunta envolvendo os três experimentos.

Todas as análises, incluindo o estudo de regressão em função dos diferentes espaçamentos e densidades, foram realizadas utilizando o programa estatístico Sisvar $^{\circledR}$ (Ferreira, 2000).

\section{Resultados e Discussão}

Foi observada diferença significativa $(\mathrm{p} \leq$ $0,01)$ para altura de planta em função do local, do espaçamento, da cultivar, além das interações local $\mathrm{x}$ cultivar e local x espaçamento. As plantas apresentaram altura média de $2,16 \mathrm{~m}$. O coeficiente de variação (CV) foi de 6,93\% para essa característica (Tabela 2). 
Independentemente do espaçamento entrelinhas e da densidade de plantas utilizada, os experimentos conduzidos em Jaíba proporcionaram maior altura de plantas (Tabela 2). Comparando as outras localidades, não foi verificada diferença em alturas das plantas para a cultivar BRS 506. Entretanto, a cultivar BRS 507 apresentou, no ensaio de Leme do Prado, plantas mais altas quando comparada as de Nova Porteirinha.

A diferença na altura de plantas observada nas localidades deve-se, principalmente, às condições edafoclimáticas distintas e à diferença genética das cultivares. Os dados climatológicos apresentados na Figura 1 demonstram que as temperaturas não foram limitantes para o sorgo sacarino na maioria das localidades, pois, de acordo com Magalhães \& Durães (2003), a cultura exige temperaturas superiores a $21{ }^{\circ} \mathrm{C}$ durante seu ciclo para um crescimento e um desenvolvimento adequados.

O trabalho conduzido em Leme do Prado apresentou decréscimo na temperatura a partir da primeira quinzena de janeiro, com valores inferiores a $20{ }^{\circ} \mathrm{C}$ (Figura 1), justificando, assim, as menores alturas das plantas neste local. Essa localidade está a uma altitude de $812 \mathrm{~m}$, o que acarreta menores temperaturas quando comparada a Jaíba e a Nova Porteirinha. A quantidade de nós que determina a altura de plantas está determinada pelos genes da maturação e por sua reação ao fotoperíodo e à temperatura (Magalhães \& Durães, 2003).

Todavia, considerando o regime hídrico, notouse uma irregularidade das precipitações, em que o mês de dezembro apresentou valores superiores a $400 \mathrm{~mm}$ em todas as localidades (Figura 1). Nos meses posteriores, constatou-se uma redução nos índices pluviométricos de maiores magnitudes após janeiro, ou seja, após o sexto decêndio descrito na Figura 1. Neste período, a planta encontrava-se no segundo estádio de crescimento vegetativo (EC2), que vai da iniciação da panícula até o florescimento. A partir de $\mathrm{EC} 2$, vários processos de crescimento, se afetados, podem comprometer o rendimento do sorgo (Magalhães \& Durães, 2003).

A menor expansão celular provocada pelo estresse hídrico inibe o crescimento das plantas de sorgo (Grima \& Krieg, 1992; Taiz \& Zeiger, 2004). Sendo assim, as menores precipitações, associadas à textura francoarenosa do solo (Tabela 1), pode ter favorecido maior estresse hídrico na cultivar BRS 507 no experimento conduzido em Nova Porteirinha.

É importante salientar que os experimentos foram conduzidos em regiões semiáridas do estado de Minas Gerais, onde a maior limitação para os cultivos é a má distribuição das chuvas durante o desenvolvimento da cultura, ou seja, a maior parte da precipitação ocorre em um ou dois meses do ano.

As representações gráficas das equações de regressão para altura de plantas em função das localidades e dos espaçamentos estão apresentadas na Figura 2. Foi constatada relação linear entre a altura de plantas e os espaçamentos nos experimentos conduzidos em Leme do Prado e em Jaíba ( $\leq \leq 0,01)$. Notou-se, em Leme do Prado, um coeficiente de determinação $\left(\mathrm{R}^{2}\right)$ de $84,14 \%$, em que o aumento de $1 \mathrm{~cm}$ no espaçamento entre as fileiras proporcionou elevação de 3,4 cm no porte das plantas. Ademais, em Jaíba, o aumento de $1 \mathrm{~cm}$ no espaçamento provocou plantas $1,1 \mathrm{~cm}$ mais altas com o $\mathrm{R}^{2}$ de $98,88 \%$.

Concordando com os resultados de Nova Porteirinha, Snider et al. (2012), ao avaliarem cultivares de sorgo sacarino em diferentes arranjos de plantas e localidades dos Estados Unidos, também observaram que o espaçamento não afeta a altura das plantas. Entretanto, esses autores afirmam que a cultivar e o 
TABELA 2. Altura média de plantas (m) de duas cultivares de sorgo e em diferentes localidades.

\begin{tabular}{llll}
\hline Cultivares $^{1}$ & \multicolumn{3}{c}{ Localidades } \\
\cline { 2 - 4 } & Leme do Prado, MG & Nova Porteirinha, MG & Jaíba, MG \\
\hline BR 506 & $2,03 \mathrm{Bb}$ & $2,00 \mathrm{Ab}$ & $2,37 \mathrm{Aa}$ \\
BR 507 & $2,17 \mathrm{Ab}$ & $1,97 \mathrm{Ac}$ & $2,39 \mathrm{Aa}$ \\
\hline CV $(\%)$ & 6,93 & & \\
\hline
\end{tabular}

${ }^{1}$ Médias seguidas pela mesma letra maiúscula na coluna e minúscula na linha, não diferem significativamente entre si pelo teste de Scott-Knott.

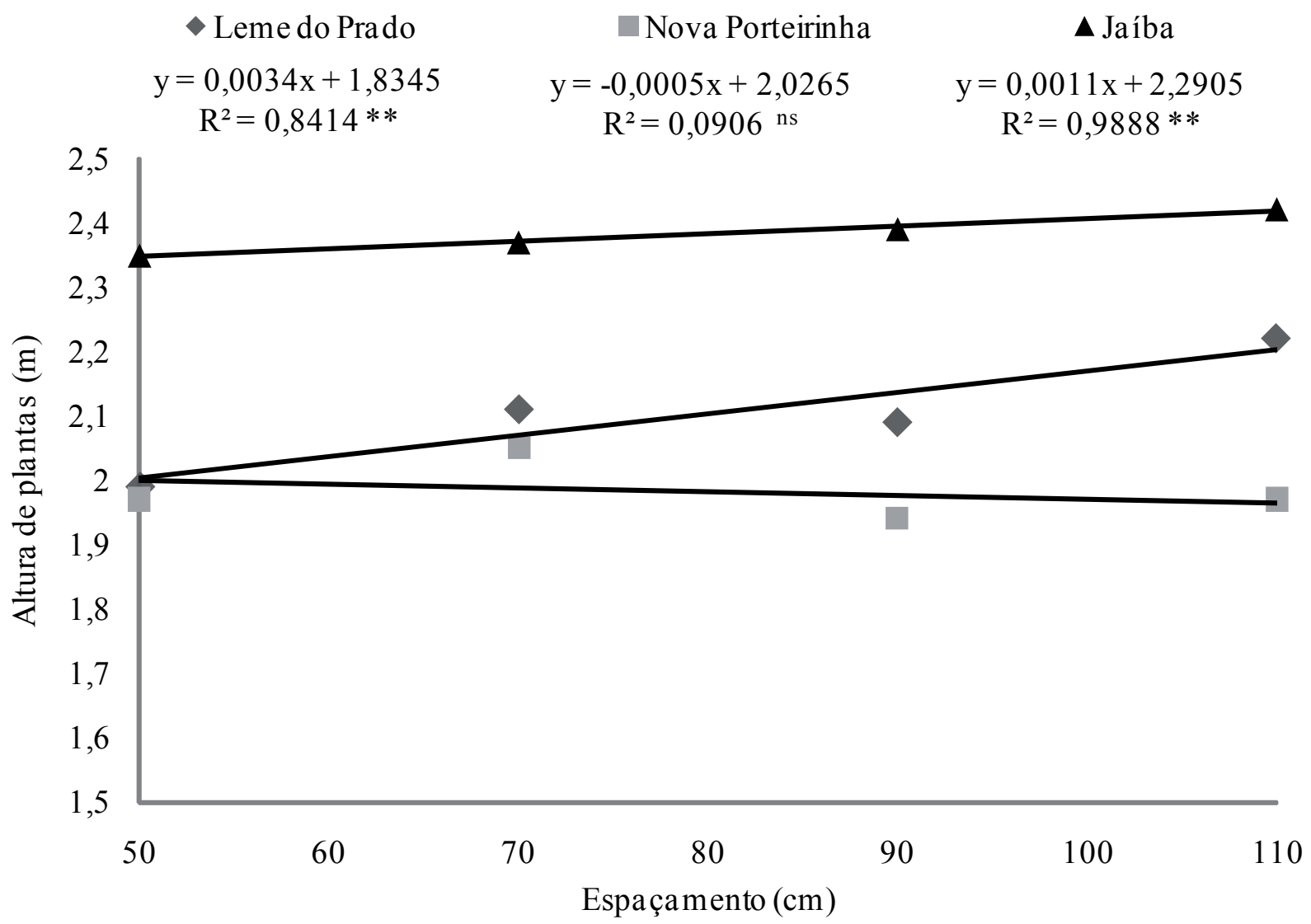

FIGURA 2. Representação gráfica das equações de regressão para altura de plantas de sorgo sacarino em fun-

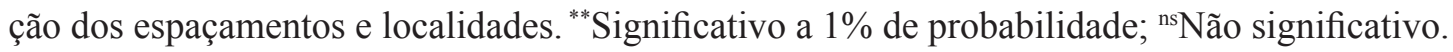

local de cultivo provocam alterações significativas para essa característica. Segundo Albuquerque et al. (2011), a diferença de resultados nos experimentos envolvendo arranjo de plantas no sorgo pode ser atribuída à cultivar e às condições climáticas prevalecentes no ano agrícola ou no local de cultivo. 
O resultado da análise de variância demonstrou diferença significativa $(\mathrm{p} \leq 0,01)$ para a produtividade de massa fresca em função do local, do espaçamento, da densidade, da cultivar, além das interações "local x cultivar" e "local x espaçamento". As plantas apresentaram produtividade de massa fresca de $32,62 \mathrm{t} \mathrm{ha}^{-1}$. O CV (\%) para essa característica foi 22,66\% (Tabela 3).

Caracterizando a produtividade de massa fresca em função das três localidades dentro dos quatro espaçamentos entre as fileiras, foram observados maiores valores no experimento conduzido em Jaíba, com valores variando de $36,44 \mathrm{t} \mathrm{ha}^{-1}$ no espaçamento $50 \mathrm{~cm}$ a $45,75 \mathrm{t} \mathrm{ha}^{-1}$ no espaçamento $110 \mathrm{~cm}$ (Tabela 3).

Os espaçamentos 50, 90 e $110 \mathrm{~cm}$ propiciaram as mesmas produtividades nos experimentos conduzidos em Leme do Prado e em Nova Porteirinha. Considerando esses dois locais, no espaçamento $70 \mathrm{~cm}$, as cultivares apresentaram maiores rendimentos em Leme do Prado (Tabela 3).

Entre as cultivares, a BRS 506 apresentou menor produtividade de massa fresca quando comparada à BRS 507 em Leme do Prado (Tabela 4). Nas outras localidades, não foram relatadas diferenças significativas. Entre as localidades, o experimento conduzido em Jaíba apresentou maiores produtividades de massa fresca.

Conforme reportado anteriormente, a cultivar BRS 507 apresentou maior altura das plantas e maior produtividade de massa fresca em Leme do Prado e o experimento conduzido em Jaíba destacou-se com plantas maiores e mais produtivas (Tabelas 2 e 4). Alguns autores demonstraram que a altura das plantas tem correlação direta com a produtividade de massa fresca de cultivares de sorgo (Zago, 1992; Rocha Junior et al., 2000; Von Pinho et al., 2007).

Os melhores resultados obtidos em Jaíba podem ser atribuídos às melhores condições de fertilidade e à textura do solo da área experimental (Tabela 1). Os solos nesse local são originados de rochas com altos teores de cálcio e potássio, conferindo alta soma de bases (SB) e alta saturação de bases (V\%). Além disso, os altos teores de argila e silte em Jaíba podem ter propiciado maior retenção da água no solo.

Ao avaliar o melhor arranjo de plantas, é importante considerar que os principais componentes de produção de etanol em cultivares de sorgo sacarino são a massa fresca, os sólidos solúveis e a massa do caldo (Teetor et al., 2011). Estes autores afirmam que tais características podem ser correlacionadas. Sendo assim, práticas agrícolas visando a seus incrementos no momento da colheita são de extrema importância.

A densidade de plantio também provocou alterações na produtividade de massa fresca $(p \leq 0,01)$. A representação gráfica da equação de regressão para a produtividade da massa fresca em função das densidades está apresentada na Figura 3.

Foi constatada relação linear $(\mathrm{p} \leq 0,01)$ entre a produtividade da massa fresca e as densidades de semeadura, sendo os coeficientes de determinação $\left(\mathrm{R}^{2}\right)$ de $86,69 \%$. Neste caso, observou-se que o aumento de mil plantas ha ${ }^{-1}$ proporcionou acréscimo de $35,3 \mathrm{tha}^{-1}$ de massa fresca (Figura 3).

Broadhead \& Freeman (1980) não verificaram efeito do aumento da população nos componentes de produção do sorgo sacarino. Já Lueschen et al., (1991) e Wortmann et al. (2010) não reportaram efeito na produção de biomassa, mas notaram aumento na altura das plantas. Snider et al. (2012) concluíram que populações superiores a 
TABELA 3. Produtividade média de massa fresca do sorgo sacarino ( $\left.\mathrm{t} \mathrm{ha} \mathrm{a}^{-1}\right)$, em função dos espaçamentos e localidades ${ }^{1}$.

\begin{tabular}{lccll}
\hline \multirow{2}{*}{ Locais } & \multicolumn{4}{l}{ Espaçamentos $(\mathrm{cm})$} \\
\cline { 2 - 5 } & 50 & 70 & 90 & 110 \\
\hline Leme do Prado, MG & $31,74 \mathrm{~b}$ & $32,11 \mathrm{~b}$ & $27,23 \mathrm{~b}$ & $27,71 \mathrm{~b}$ \\
Nova Porteirinha, MG & $28,24 \mathrm{~b}$ & $27,34 \mathrm{c}$ & $29,43 \mathrm{~b}$ & $27,90 \mathrm{~b}$ \\
Jaíba, MG & $45,75 \mathrm{a}$ & $40,03 \mathrm{a}$ & $37,54 \mathrm{a}$ & $36,44 \mathrm{a}$ \\
\hline CV (\%) & 22,66 & & & \\
\hline
\end{tabular}

${ }^{1}$ Médias seguidas pela mesma letra na coluna não diferem significativamente entre si, pelo o teste de ScottKnott.

TABELA 4. Resultados médios de produtividade de massa fresca de cultivares de sorgo sacarino ( $\left.\mathrm{t} \mathrm{ha}^{-1}\right) \mathrm{em}^{-}$ diferentes localidades ${ }^{1}$.

\begin{tabular}{llll}
\hline \multirow{2}{*}{ Cultivar } & \multicolumn{3}{c}{ Localidades } \\
\cline { 2 - 4 } & Leme do Prado, MG & Nova Porteirinha, MG & Jaíba, MG \\
\hline BRS 506 & $27,77 \mathrm{Bb}$ & $29,52 \mathrm{Ba}$ & $39,42 \mathrm{Aa}$ \\
BRS 507 & $31,62 \mathrm{Ba}$ & $26,94 \mathrm{Ba}$ & $40,46 \mathrm{Aa}$ \\
\hline CV $(\%)$ & 22,66 & & \\
\hline
\end{tabular}

${ }^{1}$ Médias com mesma letra minúscula, dentro de cada localidade, pertencem ao mesmo agrupamento, de acordo com o teste de Scott-Knott. Na horizontal, dentro de cada cultivar, médias com a mesma letra maiúscula não diferem entre si pelo teste de Scott-Knott.

116 mil sementes por hectare provocam alterações morfológicas propícias ao acamamento do sorgo sacarino, isto é, caules mais finos e plantas mais altas.

É importante destacar que, "visualmente", várias parcelas estavam com as plantas acamadas independentemente do espaçamento, da densidade ou do local. Geralmente, plantas mais altas com colmos mais finos são mais sensíveis ao acamamento devido à maior exposição da planta à força dos ventos. Como hipótese, os benefícios provenientes do arranjo de plantas na área, por exemplo, maior interceptação de luz pelas plantas, foram ocultados pela susceptibilidade dessas cultivares ao acamamento. Isso inviabiliza a colheita do sorgo para produção de etanol e deve ser melhor elucidado em futuros trabalhos envolvendo densidade de plantas em cultivares modernas.

Com base nos dados apresentados, o aumento da população proporcionou incrementos na produtividade da massa fresca para as cultivares BRS 506 e BRS 507 nas três localidades.

Trabalhos sobre o efeito da densidade de plantas no rendimento do sorgo sacarino são inconsistentes. Alguns autores destacam que taxas elevadas de semeadura propiciam incrementos na produtividade de massa; em outros casos, não é verificado nenhum efeito sobre a produtividade (Stickler \& Laude, 1960; Steiner, 1986; Habyarimana et al., 2004; Wortmann et al., 2010; Snider et al., 2012). O rendimento de sorgo sacarino, em resposta à densidade de semea- 
dura, parece ser dependente do ambiente e da cultivar (Habyarimana et al, 2004; Wortmann et al, 2010).

As representações gráficas das equações de regressão para a produtividade de massa fresca, em função dos espaçamentos entre as fileiras e das localidades, encontram-se na Figura 4. locais de cultivo, verificaram incrementos na produtividade de massa fresca, bem como incrementos no diâmetro do caule com a redução do espaçamento.

Houve diferença significativa para a massa do caldo em função do local ( $\mathrm{p} \leq 0,01)$, do espaça-

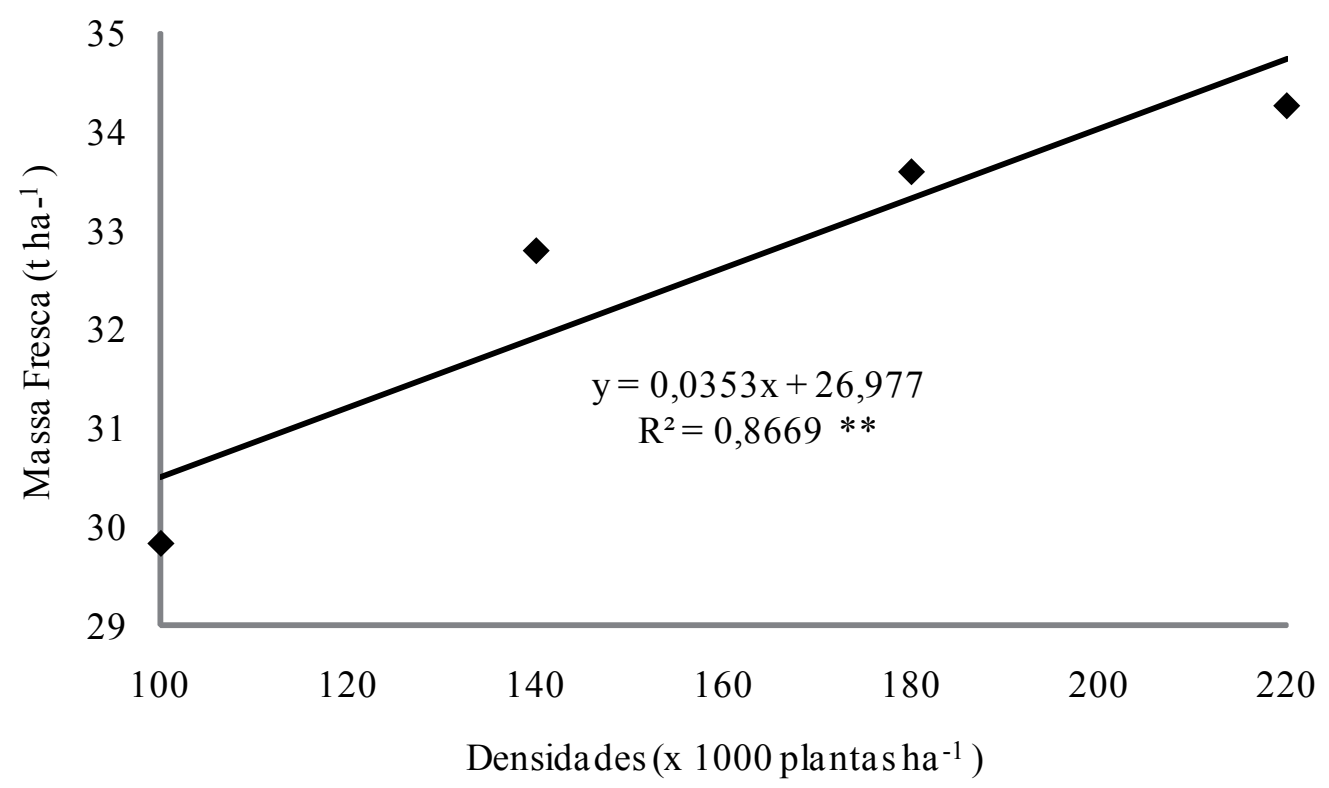

FIGURA 3. Representação gráfica das equações de regressão para a produtividade de massa fresca das cultivares de sorgo sacarino, nas quatro densidades. ${ }^{* *}$ Significativo a $1 \%$ de probabilidade

Foi observada redução na produtividade de massa fresca com o aumento do espaçamento entre as fileiras dos experimentos conduzidos em Leme do Prado $\left(\mathrm{R}^{2}=71,88 \%\right)$ e em Jaíba $\left(\mathrm{R}^{2}=89,37 \%\right)$. No primeiro local, o aumento de $1 \mathrm{~cm}$ proporcionou redução de $84,80 \mathrm{~kg} \mathrm{ha}^{-1}$ de massa fresca e, no experimento conduzido em Jaíba, a redução chegou a $152,10 \mathrm{~kg} \mathrm{ha}^{-1}$. Em Nova Porteirinha, não foi constatado efeito dos espaçamentos na produtividade de massa fresca.

Corroborando com esses resultados, Snider et al. (2012), avaliando três espaçamentos (19, 38 e $76 \mathrm{~cm}$ ) para o sorgo sacarino em diferentes mento ( $\mathrm{p} \leq 0,01)$, da densidade $(\mathrm{p} \leq 0,01)$ e das interações local x espaçamento $(\mathrm{p} \leq 0,01)$ e local x cultivar $\mathrm{x}$ espaçamento $(\mathrm{p} \leq 0,05)$. O CV foi de $28,20 \%$ para a produtividade da massa do caldo.

A produtividade média geral da massa do caldo foi 7,36 t ha-1. É importante ressaltar que o equipamento utilizado para a extração da massa do caldo foi de baixa eficiência. Sendo assim, os dados não podem ser extrapolados para situações reais de produção industrial em usinas de etanol da cana-deaçúcar.

Através do desdobramento da interação espaçamento x cultivar x local, notou-se que o experi- 


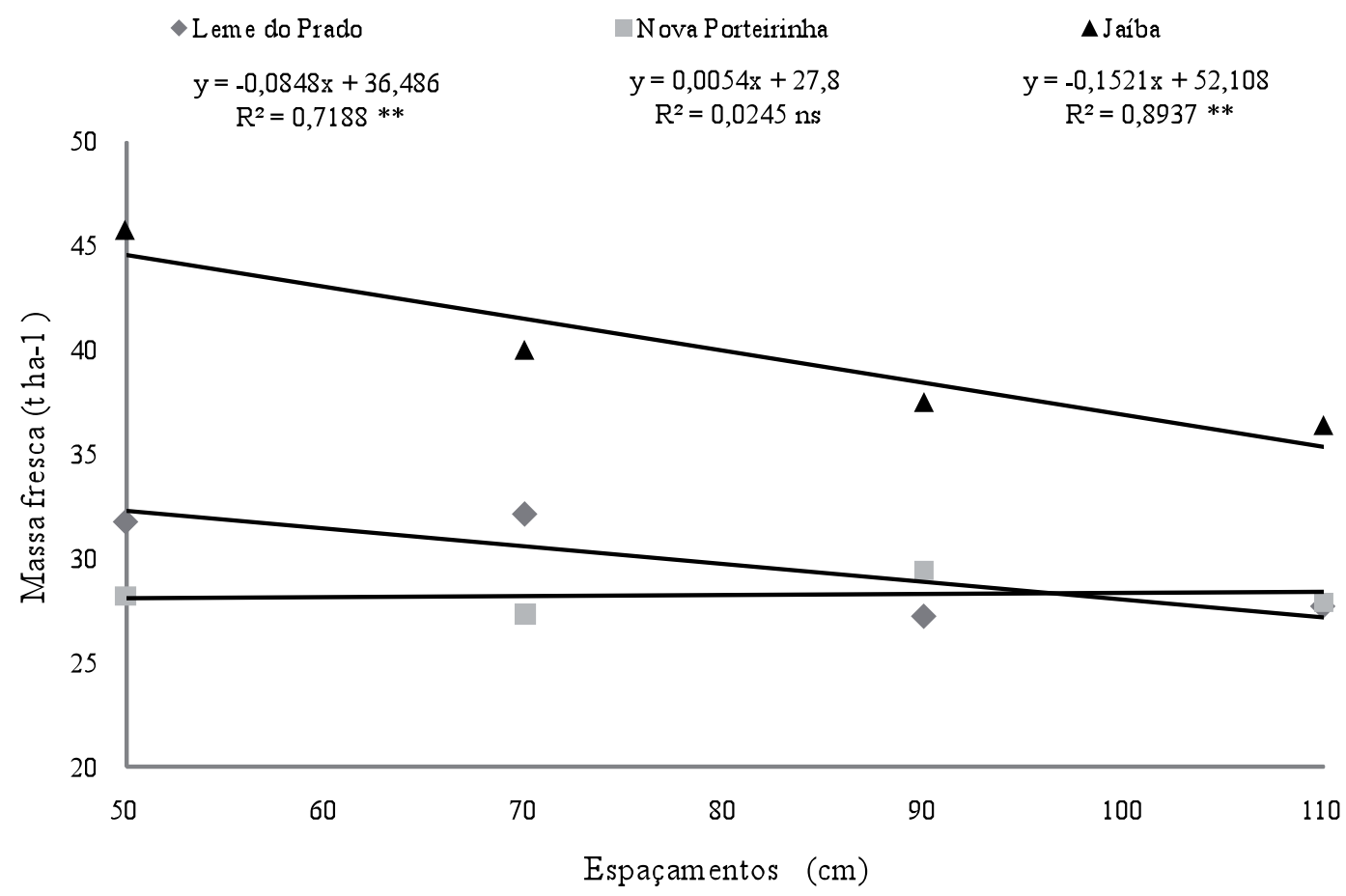

FIGURA 4. Representação gráfica das equações de regressão para a produtividade de massa fresca das cultivares de sorgo sacarino em função dos espaçamentos e localidades. ${ }^{* *}$ Significativo a $1 \%$ de probabilidade;

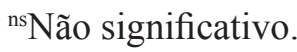

mento conduzido em Jaíba produziu maiores produtividades de massa de caldo, independentemente do espaçamento e da cultivar avaliada (Tabela 5).

Observou-se diferença entre as cultivares para produtividade da massa do caldo apenas no experimento conduzido em Jaíba nos espaçamentos 70 e $110 \mathrm{~cm}$. No menor espaçamento, a cultivar BRS 507 foi superior, com 13,43 $\mathrm{t} \mathrm{ha}^{-1}$ de caldo. Já no maior espaçamento, o BRS 506 foi superior, com 11,59 t ha-1 (Tabela 5).

Foi constatada relação linear entre a produtividade da massa do caldo e os espaçamentos na cultivar BRS 506 nos experimentos conduzidos em Leme do Prado e em Jaíba. Já para a cultivar BRS 507, foi constatada relação linear apenas para o experimento conduzido em Jaíba.
A equação de regressão para a cultivar BRS 506 no experimento conduzido em Leme do Prado demonstrou que o aumento de $1 \mathrm{~cm}$ entre as fileiras proporcionou decréscimo de $11,7 \mathrm{~kg} \mathrm{ha}^{-1}$ na produtividade da massa do caldo (Figura 5). Ainda nesta localidade, não foi observado efeito do espaçamento na cultivar BRS 507.

No experimento conduzido em Nova Porteirinha, não foi verificado efeito dos espaçamentos em nenhuma das cultivares avaliadas (Figura 5). No ensaio de Jaíba, observou-se para a cultivar BRS 506 relação quadrática $(\mathrm{p} \leq 0,05)$ entre a produtividade da massa do caldo e os espaçamentos entre as fileiras, sendo os coeficientes de determinação $\left(\mathrm{R}^{2}\right)$ de $94,30 \%$. Neste caso, observou-se que o aumento de $1 \mathrm{~cm}$ proporcionou decréscimo na produtividade até 
o espaçamento $88 \mathrm{~cm}$, atingindo-se 10,94 $\mathrm{t} \mathrm{ha}^{-1} \quad$ (Figura 5). A partir daí, verificou-se que, com o aumento do espaçamento, ocorreu acréscimo no rendimento do caldo.

O espaçamento adotado também afetou a produtividade da massa do caldo na cultivar BRS 507 no experimento conduzido em Jaíba. Foi constatada relação linear $(p \leq 0,01)$ entre a produtividade da massa do caldo e os espaçamentos, sendo os coeficientes de determinação $\left(\mathrm{R}^{2}\right)$ de $96,04 \%$. Neste caso, observou- traram, ao avaliar cultivares de sorgo sacarino sob dois arranjos de plantas (15 x 40 e 15 x $60 \mathrm{~cm})$, que as maiores produtividades de caldo foram obtidas nos menores espaçamentos e nas maiores populações.

Fixando a mesma densidade de plantas por hectare nos diferentes espaçamentos, a melhor disposição das plantas na área é obtida nos menores espaçamentos. Isto ocorre pela menor competição intraespecífica, ou seja, menor competição entre as plantas de sorgo na linha de semeadura.

TABELA 5. Produtividade média da massa do caldo $\left(\mathrm{t} \mathrm{ha}^{-1}\right)$ de duas cultivares de sorgo, em função dos espaçamentos e três localidades Leme do Prado, Nova Porteirinha e Jaíba'.

\begin{tabular}{|c|c|c|c|}
\hline \multirow{2}{*}{ Espaçamentos } & \multirow{2}{*}{ Locais } & \multicolumn{2}{|c|}{ Cultivares } \\
\hline & & BRS 506 & BRS 507 \\
\hline \multirow[t]{3}{*}{$50 \mathrm{~cm}$} & Leme do Prado, MG & $5,91 \mathrm{Ba}$ & $5,25 \mathrm{Ba}$ \\
\hline & Nova Porteirinha, $\mathrm{MG}$ & $5,53 \mathrm{Ba}$ & 4,08 Ba \\
\hline & Jaíba, MG & $13,61 \mathrm{Aa}$ & $14,13 \mathrm{Aa}$ \\
\hline \multirow[t]{3}{*}{$70 \mathrm{~cm}$} & Leme do Prado, MG & $5,70 \mathrm{Ba}$ & $4,34 \mathrm{Ba}$ \\
\hline & Nova Porteirinha, MG & 4,46 $\mathrm{Ba}$ & $5,17 \mathrm{Ba}$ \\
\hline & Jaíba, MG & $11,23 \mathrm{Ab}$ & $13,43 \mathrm{Aa}$ \\
\hline \multirow[t]{3}{*}{$90 \mathrm{~cm}$} & Leme do Prado, MG & $5,14 \mathrm{Ba}$ & $4,44 \mathrm{Ba}$ \\
\hline & Nova Porteirinha, MG & $5,18 \mathrm{Ba}$ & $4,82 \mathrm{Ba}$ \\
\hline & Jaíba, MG & $11,26 \mathrm{Aa}$ & $11,30 \mathrm{Aa}$ \\
\hline \multirow[t]{3}{*}{$110 \mathrm{~cm}$} & Leme do Prado, $\mathrm{MG}$ & $5,31 \mathrm{Ba}$ & $5,53 \mathrm{Ba}$ \\
\hline & Nova Porteirinha, MG & $4,92 \mathrm{Ba}$ & $5,12 \mathrm{Ba}$ \\
\hline & Jaíba, MG & $11,59 \mathrm{Aa}$ & $9,22 \mathrm{Ab}$ \\
\hline $\mathrm{CV}(\%)$ & 28,20 & & \\
\hline
\end{tabular}

${ }^{1}$ Médias seguidas pela mesma letra maiúscula na coluna e minúscula na linha, dentro de cada espaçamento, não diferem significativamente entre si pelo teste de Scott-Knott.

se que o aumento de mil plantas ha-1 proporcionou acréscimo de $84,3 \mathrm{~kg} \mathrm{ha}^{-1}$ de caldo.

Estes resultados corroboram os obtidos por Kumar et al. (2008) em experimento conduzido em diferentes localidades na Índia. Tais autores demons-
A representação gráfica da equação de regressão para a produtividade da massa do caldo em função das densidades está apresentada na Figura 6.

Foi constatada relação linear $(p \leq 0,05)$ entre a produtividade da massa do caldo e as 

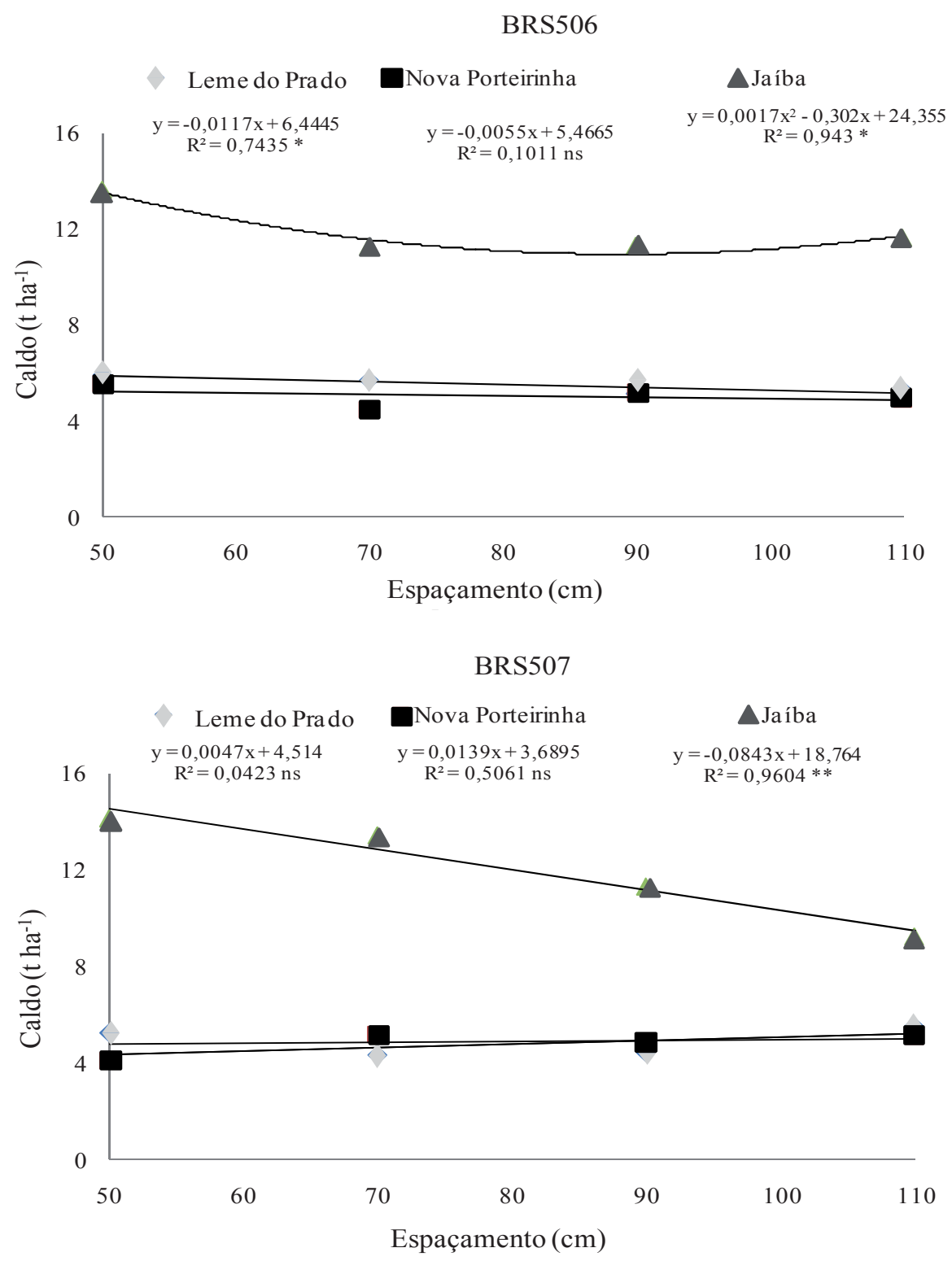

FIGURA 5. Representação gráfica das equações de regressão para a produtividade da massa do caldo das cultivares de sorgo BRS 506 e BRS 507, nos quatro espaçamentos e nas diferentes localidades. ${ }^{* *}$ Significativo

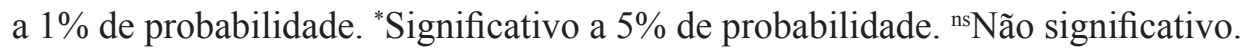

densidades de semeadura, sendo os coeficientes de determinação $\left(\mathrm{R}^{2}\right)$ de $85,16 \%$. Neste caso, observou-se que o aumento de mil plantas $\mathrm{ha}^{-1}$ proporcionou acréscimo de $9,6 \mathrm{~kg} \mathrm{ha}^{-1}$ de caldo. A diminuição do espaçamento e o aumento da densidade resultaram em aumento de produção de massa fresca e massa do caldo. Isto ocorreu devido ao maior número de plantas por área, apesar do possível decréscimo no peso de plantas individuais. 


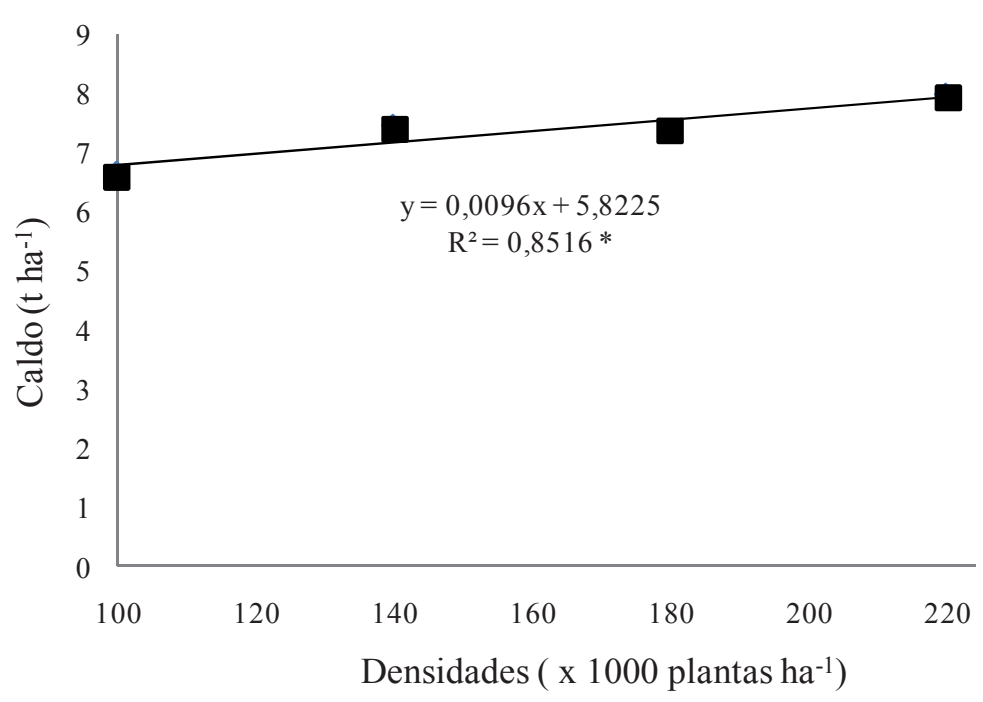

FIGURA 6. Representação gráfica da equação de regressão para a massa de caldo nas diferentes densidades, utilizando uma moenda com capacidade de extração máxima de $30 \% .{ }^{* *}$ Significativo a $1 \%$ de probabilidade. ${ }^{*}$ Significativo a $5 \%$ de probabilidade. ${ }^{\text {ns }}$ Não significativo

É importante destacar que as plantas acamadas e quebradas não foram avaliadas. Entretanto, percebeu-se grande susceptibilidade ao acamamento das cultivares no campo experimental, principalmente no experimento conduzido em Jaíba, em que as plantas apresentaram maiores produtividades.

Diversos autores relataram que o acamamento de plantas está correlacionado com o aumento da densidade (Albuquerque et al.,2011; Kumar et al., 2008; Von Pinho et al., 2007). Avaliando cultivares de sorgo (SHS 500, BRS 610, BRS 655 e $1 F$ 305) em diferentes arranjos de plantas, Albuquerque et al. (2011) concluíram que o aumento da densidade de semeadura condicionou maior acamamento das plantas em função da cultivar e do ano agrícola. Sendo assim, a recomendação de maiores densidades no sorgo sacarino deve considerar avaliações referentes ao acamamento de plantas.

Visando a maiores rendimentos de etanol, a produtividade da massa do caldo do sorgo sacarino deve conter altos teores de Brix. Considerando essa característica, foi observado efeito significativo para as fontes de variação local ( $\mathrm{p} \leq 0,01)$, cultivar ( $\mathrm{p} \leq$ $0,01)$, espaçamentos $(\mathrm{p} \leq 0,05)$, além da interação local $\mathrm{x}$ cultivar $(\mathrm{p} \leq 0,01)$. A média geral para $\mathrm{o}$ Brix foi $18,28^{\circ}$ e o CV apresentou valor de $10,15 \%$ (Tabela 6).

Comparando as duas cultivares, a BRS 506 produziu menor Brix nos experimentos de Nova Porteirinha e Jaíba (Tabela 6). Em Leme do Prado, não foram observadas diferenças entre as duas cultivares para o Brix do caldo das plantas. Isto pode ser justificado pela diferença genética das cultivares avaliadas, bem como pela estabilidade nos diferentes ambientes de avaliação.

Para as três localidades, notou-se variação no Brix da cultivar BRS 506 (Tabela 6). Neste caso, registraram-se maiores valores (18,86 Brix) em Leme do Prado e menores valores em Nova Porteirinha (16,47 Brix). Já para a cultivar BRS 507, não 
TABELA 6. Resultados médios para Brix de duas cultivares de sorgo em função da localidade ${ }^{1}$.

\begin{tabular}{llll}
\hline \multirow{2}{*}{ Cultivares } & \multicolumn{3}{c}{ Locais } \\
\cline { 2 - 4 } & Leme do Prado, MG & Nova Porteirinha, MG & Jaíba, MG \\
\hline BR 506 & $18,86 \mathrm{Aa}$ & $16,47 \mathrm{Bc}$ & $18,13 \mathrm{Bb}$ \\
BR 507 & $18,60 \mathrm{Aa}$ & $18,10 \mathrm{Aa}$ & $19,50 \mathrm{Aa}$ \\
\hline CV $(\%)$ & 10,15 & & \\
\hline
\end{tabular}

${ }^{1}$ Médias seguidas pela mesma letra maiúscula na vertical e minúscula na linha, não diferem entre si pelo teste de Scott-Knott.

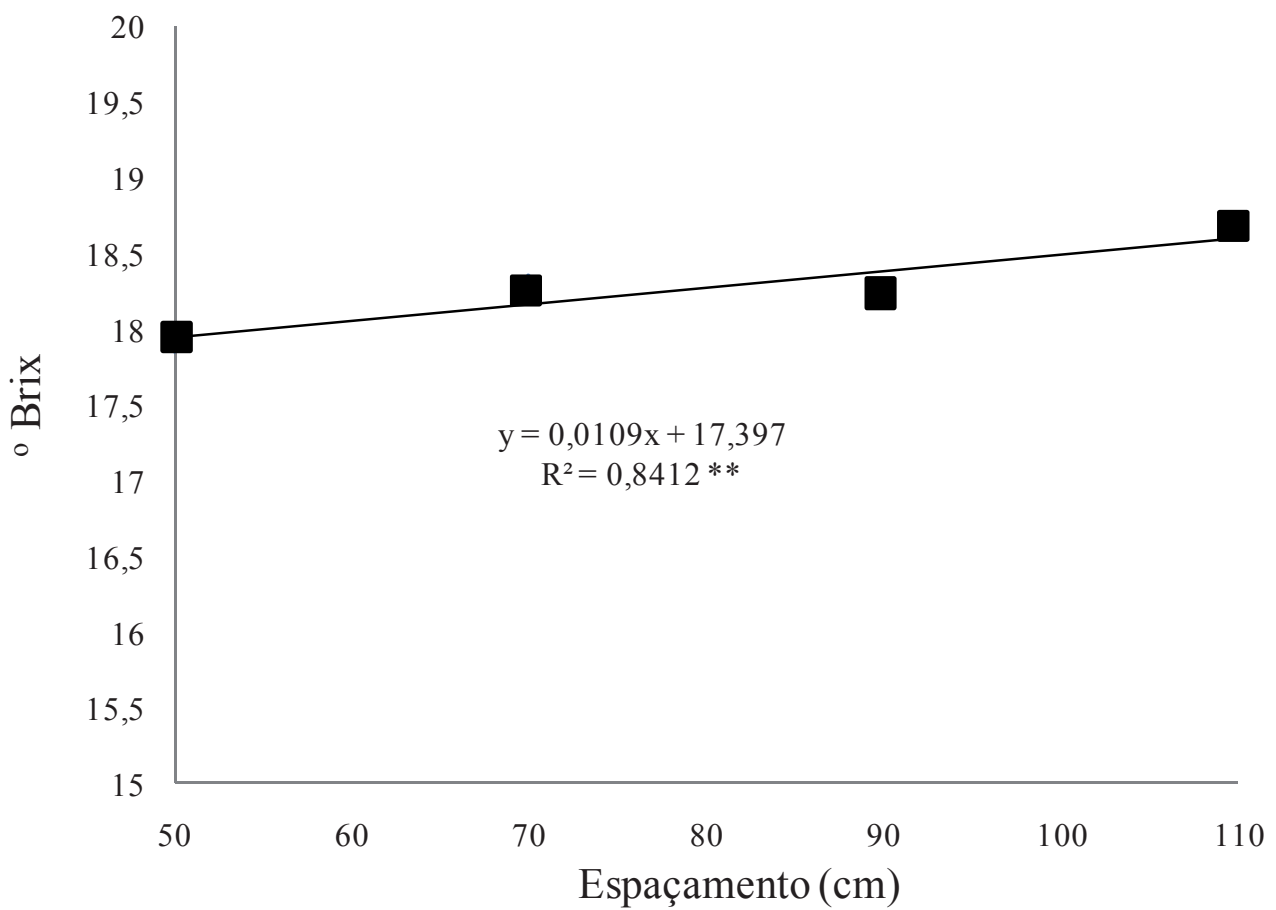

FIGURA 7. Representação gráfica da equação de regressão para o Brix do caldo nos diferentes espaçamentos.

** Significativo, a 1\% de probabilidade.

foi constatada variação no Brix entre os três locais de avaliação. De acordo com os trabalhos de Teixeira et al. (1999), o Brix do caldo do sorgo sacarino é grandemente influenciado pelo comprimento do dia e pela radiação global. Outros autores afirmam ainda que o Brix pode ser influenciado pela adubação ou pela fertilidade do solo (Kumar et al., 2008).

A representação gráfica da equação de regressão envolvendo o Brix do caldo em função dos espaçamentos entre as fileiras está na Figura 7. Foi constatada relação linear entre o ${ }^{\circ}$ Brix e os espaçamentos utilizados. Notou-se valor do coeficiente de determinação $\left(\mathrm{R}^{2}\right)$ de $84,12 \%$ e constatou-se que, com o aumento de $1 \mathrm{~cm}$, houve acréscimo de $0,011^{\circ}$ Brix.

Conforme discutido anteriormente, maiores 
espaçamentos aumentam a competição intraespecífica na linha de plantio devido ao maior número de plantas por metro. Este fato pode ter reduzido a eficiência na absorção de água, gerando maiores concentrações dos teores de sólidos solúveis (Brix) no caldo.

\section{Conclusões}

A localidade afeta a produtividade de matéria verde, a produtividade da massa do caldo e o Brix do sorgo sacarino, independentemente do arranjo de plantas.

A redução do espaçamento provoca maior produtividade de massa fresca e caldo em função do local de cultivo e reduz os teores de Brix, independentemente da localidade.

O aumento da população provoca maior produtividade de massa fresca e caldo nas duas cultivares estudadas.

A cultivar BRS 507 apresenta melhor desempenho na maioria dos locais avaliados.

\section{Agradecimentos}

À Fapemig (Fundação de Amparo à Pesquisa do Estado de Minas Gerais) o apoio financeiro para a realização do projeto e a concessão de bolsas.

\section{Referências}

ALBUQUERQUE, C. J. B.; VON PINHO, R. G. V.; RODRIGUES, J.A. S.; BRANT, R. S.; Espaçamento entre fileiras e Densidade de semeadura do Sorgo forrageiro para a região norte de Minas Gerais. Ciência e Agrotecnologia, Lavras, v. 35, n. 3, p. 494-501, 2011
BAUMHARDT, R. L.; HOWELL, T. A. Seeding practices, cultivar maturity, and irrigation effects on simulated grain sorghum yield. Agronomy Journal, Madison, v. 98, n. 2, p. 462-470, 2006.

BROADHEAD, D. M.; FREEMAN, K. C. Stalk and sugar yield of sweet sorghum as affected by spacing. Agronomy Journal, Madison, v. 72, p. 523-524, 1980.

CASELA. C. R.; BORGONOVI, R. A.; SCHAFFERT, R. E.; SANTOS, F. G. Cultivares de sorgo. Informe Agropecuário, Belo Horizonte, v. 12, n. 144, p. 4043, 1986

FERREIRA, D. F. Análises estatísticas por meio do SISVAR (Sistema para Análise de Variância) windows 4.0. In: REUNIÃO ANUAL DA REGIÃO BRASILEIRA DA SOCIEDADE INTERNACIONAL DE BIOMETRIA, 45., 2000, São Carlos. Anais... São Carlos: UFSCar, 2000. p. 255-258.

GRIMA, F. S.; KRIEG, R. Osmotic adjustment in sorghum 1, mechanisms of diurnal osmotic potential changes. Plant Physiology, Minneapolis, v. 99, n. 2, p. 577-582, 1992.

HABYARIMANA, E.; BONARDI, P.; LAURETI, D.; DI BARI, V.; COSENTINO, S.; LORENZONI, C. Multilocational evaluation of biomass sorghum hybrids under two stand densities and variable water supply in Italy. Industrial Crops and Products, Tucson, v. 20,p. 3-9, 2004.

JONES, O. R.; JOHNSON, G. L. Evaluation of a short season, high density production strategy for dryland sorghum. Texas: USDA-ARS, 1997.

KUMAR, S. R; SHROTRIA, P. K; DESHMUKH, J. P. Characterizing Nutrient Management Effect on Yield of Sweet Sorghum Genotypes. World Journal of Agricultural Sciences, Pradesh, v. 4, n. 
6, p. 787-789, 2008.

LUESCHEN, W. E.; PUTNAM, D. H.; KANNE, B. K.; HOVERSTAD, T. R.. Agronomic practices for production of ethanol from sweet sorghum. Journal of Production Agriculture, Madison, v. 4, p. 619625, 1991

MAGALHÃES, P. C.; DURÃES, F. O. M. Ecofisiologia da produção de sorgo. Sete Lagoas: EMBRAPACNPMS, 2003. 4 p. (EMBRAPA-CNPMS. Comunicado técnico, 87).

VON PINHO, R. G.; VASCONCELOS, R. C. de; BORGES, I. D.; RESENDE, A. V. Produtividade e qualidade de silagem de milho e sorgo em função da época de semeadura. Bragantia, Campinas, v. 66, n. 2, p. 235-245, 2007

PRABU, C. S.; MURUGESAN, A. G. Potential utilization of sorghum field waste for fuel ethanol production employing Pachysolen tannophilus and Saccharomyces cerevisiae. Bioresource Technology, Tamil Nadu, v. 102, n. 3, p. 2788 $-2792,2011$.

ROCHA JUNIOR, V. R.; GONÇALVES, L. C.; RODRIGUES, J.A. S.; BRITO,A. F.; RODRIGUES, N. M.; BORGES, I. Avaliação de sete genótipos de sorgo (Sorghum bicolor L.) para produção de silagem. Arquivo Brasileiro de Medicina Veterinária e Zootecnia, Belo Horizonte, v. 52, n. 5,2000 .

SANTOS, F. G. Sorgo Sacarino para Produção de alcool. Sorgo: Uma opção agrícola. Informe Agropecuário, Belo Horizonte, v. 5, n. 56, p. 4447, 1979.

SILVA, A. F. Métodos Culturais. InformeAgropecuário, Belo Horizonte, v. 5, n. 56, p. 19-21, 1979.

SNIDER, J. L; RAPER, R. L; SCHWAB. The effect of row spacing and seeding rate on biomass production and plant stand characteristics of non-irrigated photoperiod-sensitive sorghum. Industrial Crops and Products, Tucson, v. 37, p. 527-535, 2012.

STEINER, J. L. Dryland grain sorghum water use, light interception, and growth responses to planting geometry. Agronomy Journal, Madison, v. 78, p. 720-726, 1986.

STICKLER, F. C.; LAUDE, H. H. Effect of row spacing and plant population on performance of corn, grain sorghum and forage sorghum. Agronomy Journal, Madison, v. 52, p. 275-277, 1960.

TAIZ, L.; ZEIGER, E. Fisiologia vegetal. Porto Alegre: Artmed, 2004. 722 p.

TEIXEIRA, C. G; JARDINE, J. G; ZARONE, M. H. Influência da época de corte sobre o teor de açúcares de colmos de sorgo sacarino. Pesquisa Agropecuária Brasileira, Brasília, DF, v. 34, n. 9, p. 1601-1606, 1999.

TEETOR, V. H.; DUCLOS, D. V.; YOUMG, K. M.; CHAWHUAYMAK, J.; RILEY, M. R.; RAY, D. T. Effects of planting date on sugar and ethanol yield of sweet sorghum grown in Arizona. Industrial Crops and Products, Tucson, v. 34, n. 2, p. 12931300, 2011.

WORTMANN, C. S.; LISKA, A. J.; FERGUSON, R. B.; LYON, D. J.; KLEIN, R. N.; DWEIKAT, I. Dryland performance of sweet sorghum and grain crops for biofuel in Nebraska. Agronomy Journal, Madison, v. 102, p. 319-326, 2010.

ZAGO, C. P. Utilização do sorgo na alimentação de ruminantes. In: EMPRESA BRASILEIRA DE PESQUISA AGROPECUÁRIA. Manejo cultural do sorgo para forragem. Sete Lagoas, 1992. n.17, p.9-26, 1992. 